\title{
Removal of a migrated lumen-apposing metal stent and endoscopic closure of a gastrocolonic fistula
}

An 85-year-old woman presented with a 3-month history of weight loss and vomiting due to a large pancreatic fluid collection arising from the body of the pancreas. Diagnostic endoscopic ultrasound (EUS) confirmed the fluid was acellular with elevated amylase and low carcinoembryonic antigen, compatible with a pancreatic pseudocyst. As the patient remained symptomatic, EUSguided cystgastrostomy with a $10-\mathrm{mm}$ Hot AXIOS stent (Boston Scientific, Marlborough, Massachusetts, USA) was performed via the stomach using a standard approach [1 - 3], and $1 \mathrm{~L}$ of straw-colored fluid drained immediately into the stomach. Following cyst drainage, the patient improved clinically and was discharged home the next day.

Abdominal computed tomography 1 month later, prior to stent removal, showed resolution of the pancreatic pseudocyst, but unexpectedly demonstrated that the stent had migrated into the adjacent colon, creating a gastrocolonic fistula ( $\vee$ Video 1 ).

To enable endoscopic removal of the migrated stent, we performed sequential esophagogastroduodenoscopy (EGD) and colonoscopy, under general anesthesia, following full bowel preparation. EGD confirmed that the proximal flange of the stent was within the body of the stomach, draining feculent material. Gastrografin (Bayer, Reading, UK) was injected into the stent via an endoscopic retrograde cholangiopancreatography (ERCP) cannula and confirmed a communication with the colon. At colonoscopy with the patient lying in the supine position, the stent was located at $50 \mathrm{~cm}$, just proximal to the splenic flexure. The colon was tattooed before stent removal, in case of

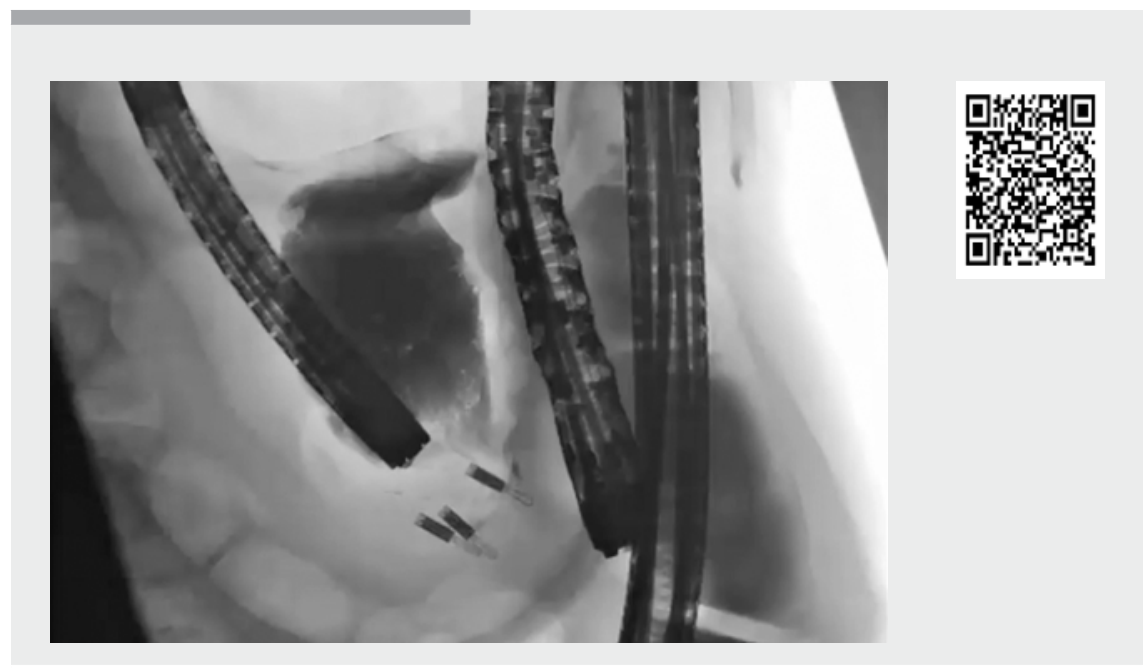

$\checkmark$ Video 1 Removal of a migrated lumen-apposing metal stent from the colon, followed by endoscopic closure of a gastrocolonic fistula.

loss of position. The stent was then removed from the stomach using grasping forceps and the fistula was closed using multiple SureClips (Micro-Tech Europe, Düsseldorf, Germany) from the stomach and colonic sides. Subsequent Gastrografin injection on both sides of the fistula tract confirmed effective endoscopic closure of the defect. The patient began eating and drinking the next day and was discharged home 2 days later.

Outpatient review 3 months later confirmed that the patient had no ongoing symptoms or sequelae following endoscopic closure of the fistula.

Endoscopy_UCTN_Code_CPL_1AL_2AD

\section{Competing interests}

None
The authors

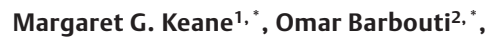
David Reffitt ${ }^{3}$, Deepak Joshi ${ }^{1}$, Stephen Gregory ${ }^{4}$, Andreas Prachalias ${ }^{2}$, John Devlin ${ }^{1}$

1 Hepatology, Institute of Liver Studies, King's College Hospital, London, United Kingdom

2 HPB Surgery, Institute of Liver Studies, King's College Hospital, London, United Kingdom

3 Gastroenterology, University Hospital Lewisham, London, United Kingdom

4 Radiology, Institute of Liver Studies, King's College Hospital, London, United Kingdom

Corresponding author

John Devlin, MD

Institute of Liver Studies, King's College Hospital, Denmark Hill, London, SE5 9RS, United Kingdom Fax: +44-20-32999000

john.devlin@nhs.net

\footnotetext{
* These authors contributed equally to this work.
} 
Bibliography

[1] Keane MG, Sze SF, Cieplik N et al. Endoscopic versus percutaneous drainage of symptomatic pancreatic fluid collections: a 14-year experience from a tertiary hepatobiliary centre. Surg Endosc 2016; 30: 3730-3740

[2] van Brunschot S, van Grinsven J, van Santvoort $\mathrm{HC}$ et al. Endoscopic or surgical stepup approach for infected necrotising pancreatitis: a multicentre randomised trial. Lancet 2018; 391: 51 - 58

[3] Venkatachalapathy SV, Bekkali N, Pereira S et al. Multicenter experience from the UK and Ireland of use of lumen-apposing metal stent for transluminal drainage of pancreatic fluid collections. Endosc Int Open 2018; 6: E259-E265
DOI https://doi.org/10.1055/a-1011-3869

Published online: 2.12.2019

Endoscopy 2020; 52: E170-E171

(C) Georg Thieme Verlag KG

Stuttgart · New York

ISSN 0013-726X
ENDOSCOPY E-VIDEOS

https:/|eref.thieme.de/e-videos

Endoscopy E-Videos is a free access online section, reporting 1.2. on interesting cases and new techniques in gastroenterological endoscopy. All papers include a high quality video and all contributions are freely accessible online.

This section has its own submission website at

https://mc.manuscriptcentral.com/e-videos 